\title{
Brainstem Activity Predicts Attachment-Related Anxiety
}

\author{
Yoshiaki Kikuchi ${ }^{\dagger}$, Yohan Matsutani, Kumiko Mori, Kenji Hanada, Yuko Shirakawa, Maki Shirato, Madoka Noriuchi
}

\begin{abstract}
Objective: Attachment security serves as a critical resource for individuals to preserve relationship quality. However, insecure attachment interrupts it and seriously influences mental/physical health. Therefore, it is important to clarify the correlations between brain activity and attachment-related anxiety and its avoidance.
\end{abstract}

Methods: We investigated these correlations in healthy male subjects by using functional magnetic resonance imaging (fMRI) while they were viewing their partner.

Results: The brain regions that were significantly activated for the partner vs. unknown females were the anterior cingulate cortex (ACC), posterior cingulate cortex (PCC), dorsal raphe nucleus (DRN), pontine raphe nucleus (PRN), and locus coeruleus (LC) in a whole-brain analysis. A region of interest (ROI) analysis showed that the DRN, periaqueductal grey (PAG), hypothalamus, anterior insula (AIC), substantia nigra/ventral tegmental area (SN/VTA), ACC, PCC and intraparietal sulcus (IPS) were significantly activated. Furthermore, activity in the DRN, SN/VTA, and LC negatively correlated with attachment-related anxiety.

Conclusions: There were individual differences in the correlations between the brainstem activity and attachment-related anxiety, although brain activity in our subjects was more similar to that observed in long-term intense romantic love and maternal love compared to that in early-stage romantic love. These brainstem regions are the primary sites of neurotransmitters which modulate basic functions of survival, and also play key roles for maintenance of secure relationships with a partner. This finding might be useful to assessment of the risk of breakdowns by factors of the attachment style.

\section{Keywords}

Romantic love, Attachment anxiety, dorsal raphe nucleus (DRN), locus coeruleus (LC), substantia nigra/ventral tegmental area (SN/VTA)

\section{Introduction}

Romantic love is one of the greatest sources of natural rewards, and pair bonds have enabled humanity to survive and flourish. Three different phases in romantic relationships have been defined (Garcia, 1998). The first phase is called "being in love," which is characterized by high passion, a rapid rise in intimacy, and increased commitment [1], and usually lasts around half a year. Love, during this phase, has the characteristics of both excitation and stress $[2,3]$, which is caused by insecurity and can lead to mood changes via elevation of cortisol levels. After several months [1,3-5], the initial phase of euphoria, excitation, and stress evolves into a phase of "passionate love" [1], which is dominated by feelings of safety, calm, and balance [3]. Levels of several neuroendocrine factors, which had been abnormal in early romantic love, including neural growth factor (NGF) [6], platelet

Department of Frontier Health Science, Division of Human Health Sciences, Graduate School of Tokyo Metropolitan University, Tokyo, Japan

${ }^{\dagger}$ Author for correspondence: Professor Yoshiaki Kikuchi, PhD \& DMedSci, Department of Frontier Health Science, Division of Human Health Sciences, Graduate School of Tokyo Metropolitan University, 7-2-10, Higashi-Ogu, Arakawa-Ku, Tokyo, 116-0012, Japan, Tel: +81-3-3819-7270, email: ykikuchi@tmu.ac.jp 
serotonin transporter [4], and abnormalities in the hypothalamic-pituitary-adrenaline (HPA)axis [5], have by this time returned to normal. In this second phase, passion remains high, and intimacy and commitment continue to steadily increase [1]. Stress is decreased, which may result in several health benefits [7]. In addition, oxytocin and vasopressin are believed to be the major neurochemical factors during this phase because they are involved in the formation of strong pair bonds between the couple [3]. The phase of passionate love usually lasts several years before evolving into "companionate love." This phase is characterized by a decrease in passion, whereas intimacy and commitment remain high [1]. Again, oxytocin and vasopressin are thought to be the dominant hormones, reinstating and maintaining pair bonds between the couple [3].

Neuroimaging studies have shown similarities and differences in brain activity between the early-stage intense romantic love ( half a year) [8] and the long-term intense romantic love ( $\sim 20$ years) phases [9]. Although brain regions involved in the dopamine reward system including SN/VTA were commonly activated in both forms of love, serotonergic DRN activity was found in long-term romantic but not early-stage romantic love. This latter finding supports the view that long-term romantic love is characterized by security and calm [3], whereas early-stage romantic love is characterized by insecurity and stress [2,3]. Furthermore, brain activity in long-term intense romantic love was shown to be similar to that observed in maternal love. It has been shown that several brain regions including the SN/VTA, DRN, insula, ACC and PCC are commonly activated in maternal love (Bartels \& Zeki, 2004) and long-term intense romantic love [9].

In addition to the duration/stage of a relationship, its quality is highly important for maintaining appropriate partner relationships. Relationship quality is associated with physical health, life satisfaction, stress-buffering, self-esteem, and psychological well-being [10-13]. In addition, low relationship quality may increase the risk of breakdown of intimate relationships including divorce and separation, and even the risk of suicide after breakdowns. Among the various factors influencing relationship quality, individual differences in attachment style are considered to be specifically important. In general, there are individual differences in attachment style along two continuous dimensions: Attachmentrelated anxiety and attachment-related avoidance
[14]. The anxiety dimension reflects the degree to which an individual is worried about being rejected, abandoned, or unloved. The avoidance dimension reflects the degree to which an individual avoids intimacy and interdependence with others. Individuals with a secure attachment style are low in both avoidance and anxiety; they are comfortable with intimacy and confident that they are loved and valued by others. In contrast, various forms of insecure attachment styles are characterized by high levels of anxiety, avoidance, or both. Attachment insecurity consistently predicts relationship dissatisfaction [15-18]. For example, anxious people tend to desire greater intimacy than they report having, because they cannot achieve the intense intimacy they want or because their desire for excessive closeness pushes away their partner [19]. In addition, individuals high in attachment anxiety are more reactive to day-to-day changes in their partners' behavior. It is suggested that this intense focus on dayto-day relationship events may explain why anxious individuals and their partners experience less relationship quality; their relationships feel more turbulent and less stable because they focus on daily events rather than on long-term experiences [20]. These facts suggest that highly anxious individuals show different brain activity involved in emotion regulation compared to less anxious individuals.

Based on these considerations, we hypothesized that more anxious individuals would show lower activation in the brainstem regions that are the primary sites of several neurotransmitters important for emotion regulation such as serotonin compared to less anxious individuals, despite the likelihood that the love-related brain regions, such as the SN/VTA would be more activated even only by viewing their partner's face, compared with the faces of unknown females. To investigate individual differences in attachment style, we examined healthy male participants who reported that they loved their partner at the time of the fMRI experiment, irrespective of their age, their marital/relationship duration, and whether or not they were married.

\section{Materials and Methods \\ - Participants \\ Participants were 17 Japanese adult males, aged 22 - 43 years $(31.4 \pm 7.7)$, who were currently in a marital/romantic relationship and reported being in love; mean relationship duration was 5.6 \pm 5.4 years $(0.3-18.0)$. Eleven participants were}


married to their partners (marital duration $5.2 \pm$ 5.9 years, age $35.0 \pm 6.8$ years), and six were not (relationship duration $1.7 \pm 1.3$ years, age 24.8 \pm 3.7 years). All participants were right-handed according to the Chapman test $(13.7 \pm 1.3)$, and no participant reported being on medication. This study was approved by the Research Ethics Committee of Tokyo Metropolitan University and all participants provided their written informed consent before participating in this study.

\section{- Experimental design and procedures}

Participants viewed the photo stimuli in the MRI scanner via goggles that allowed the photos to be projected. Two kinds of stimuli were presented in an alternating block design for a total of 363 $\sec (6.05 \mathrm{~min})$ : (a) romantic partner (five kinds of photos of the participant's partner's face), and (b) control (photos of five different unknown female faces). Each stimulus was presented for 3 sec with a 3-sec interval. Stimulus presentation order was counterbalanced across participants. Each photo was randomly presented six times.

\section{- fMRI data analysis}

Scanning was conducted using a 3.0 T MRI system (Achieva Quasar Dual, Philips). BOLD T2*-weighted MR signals were measured using a gradient echo-planar imaging (EPI) sequence $(\mathrm{TR}=4,000 \mathrm{msec}, \mathrm{TE}=35 \mathrm{msec}$, flip angle $=90^{\circ}, \mathrm{FOV}=23 \mathrm{~cm}^{2}$, scan matrix $=128 \times 128$, slice thickness $=6 \mathrm{~mm}, 20$ slices per volume). Image processing was carried out using Statistical Parametric Mapping software (SPM8, Wellcome Department of Imaging Neuroscience, London, UK; http://www.fil.ion. ucl.ac.uk/spm/software/spm8). EPI images were realigned and normalized based on the MNI (Montreal Neurological Institute) stereotactic space. Normalized images were smoothed using an $8-\mathrm{mm}$ full-width half-maximum Gaussian kernel. The data were temporally convolved with the hemodynamic response function (HRF) and high-pass filtered with a cutoff period of $128 \mathrm{sec}$. Each of the visual stimuli (partner and control) was modeled using a separate regressor. In the second-level between-subjects whole-brain analysis, we tested whether each of the contrasts (partner vs. control and control vs. partner) was significant, with a height threshold of $\mathrm{p}<$ 0.001 and an extent threshold of $\mathrm{p}<0.05$ (FDR, corrected). For the ROI analysis, we set the brain regions which had been identified in the studies on early-stage intense romantic love by Aron et al. long-term intense romantic love by
Acevedo et al. romantic love by Bartels and Zeki and maternal love by Bartels and Zeki as a set of spherical regions of interest (ROIs; radius $5 \mathrm{~mm}$ ) in the contrast of the partner vs. control, and tested their significance by using a small-volume correction (SVC; $\mathrm{p}<0.05$, FWE) [8,9,22].

\section{- Analysis of subjective ratings}

The participants were also asked to complete the following four questionnaires: The Passionate Love Scale (PLS) [23], the NEO-Five Factor Inventory (NEO-FFI) [24], the Experiences in Close Relationships inventory (ECR; Fraley et al., 2000 [25]), and the Brief Core Schema Scale (BCSS; Fowler et al., 2006). The PLS scale was specifically designed to assess the cognitive, emotional, and behavioral components of passionate love. We confirmed the difference between partners and controls using a paired-t test $(\mathrm{p}<0.05)$. The NEO-FFI was administered to assess the constellation of traits defined by the Five Factor Theory of Personality (i.e., "openness," "conscientiousness," "extraversion," "agreeableness," and "neuroticism”). The ECR is designed to assess individual differences with respect to attachment-related anxiety (i.e., the extent to which people are insecure vs. secure about the availability and responsiveness of romantic partners) and attachment-related avoidance (i.e., the extent to which people are uncomfortable being close to others vs. secure depending on others) [26,27], with 18 items rated on a 7 -point scale from 1 (not very true of me) to 7 (very true of me). The BCSS includes 24 items assessing beliefs about the self and others that are assessed on a 5-point rating scale $(0-4)$. Four scores are obtained: Negative-self, positiveself, negative-others, and positive-others.

Next, to assess the relationship between brain activity and the subjective ratings, we conducted simple regression analyses with the eigenvariate value for each of the spherical ROIs (radius: 5 $\mathrm{mm}$ ) whose center was the peak voxel in each cluster showing significant activity in the wholebrain partner vs. control contrast and the ROI set by the SVC test as the dependent variable, and the PLS as the independent variable $(\mathrm{p}<0.05)$. In addition, we conducted multiple regression analyses with the eigenvariate values for the above-mentioned brain regions as the dependent variable, and the ECR items ("anxiety" and "avoidance") as independent variables ( $\mathrm{p}<0.05)$. Furthermore, we conducted multiple regression analyses with each attachment anxiety and avoidance as dependent variables, and each BCSS 
item and NEO-FFI item as the independent variable. We checked the residuals for all regression analyses by performing the ShapiroWilks $(\mathrm{S}-\mathrm{W})$ test of normality $(\mathrm{p}<0.05)$, and calculated the Durbin-Watson statistic for the null hypothesis of no autocorrelation. Statistical analysis was carried out using SPSS version 21.0 software (SPSS, INC., Chicago, IL).

\section{Results}

\section{- Subjective ratings}

The mean partner PLS score was $109.88 \pm 18.09$, which indicates "extremely passionate love" [23]. In contrast, the mean score for controls was $21.26 \pm 12.80$, indicating "extremely cool." Compared with the controls, the participants showed significantly higher PLS scores for their partners (paired-t test; $\mathrm{t}=19.36, \mathrm{df}=16$, $\mathrm{p}<0.001)$. Average scores for ECR anxiety and avoidance were $3.73 \pm 0.95$ and $3.64 \pm$ 1.05 , respectively. Moreover, the frequency of anxiety and avoidance showed a normal distribution (anxiety: S-W statistic $=0.963, \mathrm{p}$ $=0.686 /$ avoidance: $\mathrm{S}-\mathrm{W}$ statistic $=0.983, \mathrm{p}=$ 0.979; Figure 1). Average NEO-FFI scores for "openness," "conscientiousness," "extraversion," "agreeableness," and "neuroticism" were 32.3 $\pm 6.2,27.8 \pm 7.7,27.4 \pm 8.6,30.2 \pm 4.8$, and $24.7 \pm 7.1$, respectively. Average BCSS scores for "self-negative," "self-positive," "negative-others" and "positive-others" were $3.35 \pm 2.28,6.94 \pm$ $4.75,1.82 \pm 3.03$ and $8.82 \pm 4.94$, respectively.

"Attachment anxiety" scores were positively correlated with "neuroticism" (NEO-FFI; adjusted $\mathrm{R}^{2}=0.219, \mathrm{t}=2.343, \mathrm{p}=0.033$; $\mathrm{S}-\mathrm{W}$ statistic $=0.929, \mathrm{p}=0.210 ; \mathrm{D}-\mathrm{W}$ statistic $=1.464$ ) and "self-negative" scores (BCSS; adjusted $\mathrm{R}^{2}=0.433, \mathrm{t}=3.707, \mathrm{p}=0.002 ; \mathrm{S}-\mathrm{W}$ statistic $=0.958, \mathrm{p}=0.603 ; \mathrm{D}-\mathrm{W}$ statistic $=$
2.179), and "attachment avoidance" scores were negatively correlated with "extraversion" (NEOFFI; adjusted $\mathrm{R}^{2}=0.587, \mathrm{t}=-4.005, \mathrm{p}=0.001$; $\mathrm{S}-\mathrm{W}$ statistic $=0.934, \mathrm{p}=0.258 ; \mathrm{D}-\mathrm{W}$ statistic $=$ 2.421), showing no significant correlations with BCSS scores.

\section{- Partner vs. control contrast}

As shown in Table 1, Figure 2 and 3, the brain regions significantly activated in the whole brain for the partner vs. control contrast were the right ACC, PCC, DRN, PRN, and LC. In contrast, there was no brain region significantly activated for the control vs. partner contrast. ROI analyses showed that the DRN ((2 -26 -22), $\mathrm{p}=0.002$, FWE, long-term love (Acevedo et al., 2011 [9]); (2 -24-18), $\mathrm{p}=0.003$, FWE, long-term love (Acevedo et al., 2011 [9]); (-2 -24 -16), $\mathrm{p}=0.011$, FWE, long-term love (Acevedo et al., 2011 [9]); Figure 4), the PAG ((2 -32 -24) [Talairach coordinates: TAL]: $(3-35-28)$ [MNI], $\mathrm{p}=0.000, \mathrm{FWE}$, long-term love [9] (Acevedo et al., 2011 [9]) \& maternal love (Bartels and Zeki, 2004 [22]); Figure 4), the hypothalamus ((2-8 -6), p = 0.020, FWE, longterm love (Acevedo et al., 2011 [9]); Figure 4); the anterior insula (AIC) ((-38 8 -14), $\mathrm{p}=0.002$, FWE, long-term love (Acevedo et al., 2011 [9]); Figure 4), the SN/VTA ((4 -20 -16), $\mathrm{p}=0.009$, FWE, long-term love (Acevedo et al., 2011 [9]); $\left(\begin{array}{lll}14 & -22 & -14\end{array}\right)$ [TAL]: $\left(\begin{array}{lll}16 & -23 & -18\end{array}\right)$ [MNI], $\mathrm{p}=$ 0.035 , FWE, maternal; Figure 5$)$, the ACC (($102630)$ [TAL]: (-10 32 26) [MNI], $\mathrm{p}=0.015$, FWE, maternal love (Bartels and Zeki, 2004 [22]); (-4 30 24) [TAL]: (-3 36 19) [MNI], p $=0.003$, FWE, romantic; (5 25 24) [TAL]: (7 31 19) [MNI], $p=0.004$, FWE, early-stage romantic love (Aron et al., 2005 [8]); Figure 4), the intraparietal sulcus (IPS)/inferior parietal cortex ( (30 -74 30) [TAL]: (34 -7436) [MNI], $\mathrm{p}=0.001$, FWE, maternal love (Blank and Zeki,

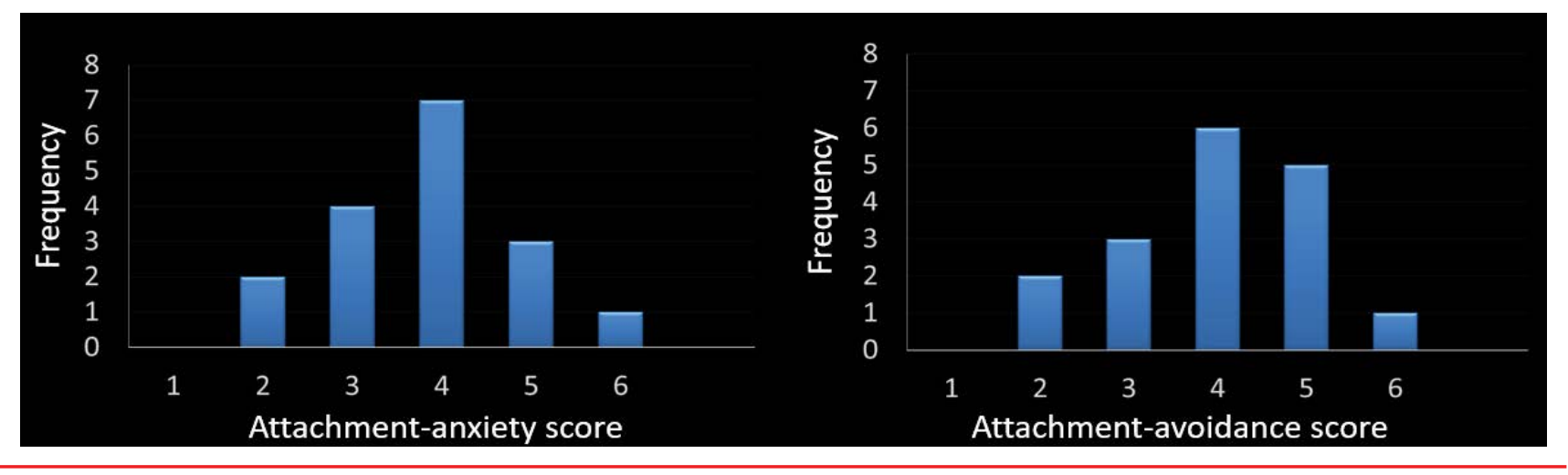

Figure 1: Frequency distribution of attachment-related anxiety and avoidance scores in all subjects. 


\begin{tabular}{|c|c|c|c|c|c|c|}
\hline \multirow[t]{2}{*}{ L/R } & \multirow[t]{2}{*}{ Brain region } & \multicolumn{3}{|c|}{ MNI coordinates } & \multirow[t]{2}{*}{ voxels } & \multirow[t]{2}{*}{ T-value } \\
\hline & & $\mathbf{x}$ & $\mathbf{y}$ & $\mathbf{z}$ & & \\
\hline \multicolumn{7}{|l|}{ Partner vs. Control } \\
\hline \multirow[t]{2}{*}{$\mathbf{R}$} & anterior cingulate gyrus & 2 & 38 & 20 & 110 & 4.73 \\
\hline & & 4 & 26 & 24 & & 4.15 \\
\hline \multirow[t]{2}{*}{$\mathbf{L}$} & posterior cingulate gyrus & -4 & -22 & 32 & 367 & 4.98 \\
\hline & & -4 & -22 & 44 & & 4.78 \\
\hline $\mathbf{R}$ & posterior cingulate gyrus & 6 & -16 & 32 & & 7.15 \\
\hline \multirow[t]{2}{*}{$\mathbf{R}$} & pontine raphe nucleus & 0 & -24 & -26 & 107 & 5.09 \\
\hline & dorsal raphe nucleus & 6 & -32 & -24 & & 6.57 \\
\hline $\mathbf{R}$ & locus coeruleus & 6 & -26 & -16 & & 4.78 \\
\hline Control vs. Partner & none & & & & & \\
\hline
\end{tabular}



Figure 2: Sagittal view ( $x=2 \mathrm{~mm}$ ) of whole-brain activity. The ACC, PCC, and PRN were significantly activated by viewing the partner's face compared with viewing the face of unknown females' faces.

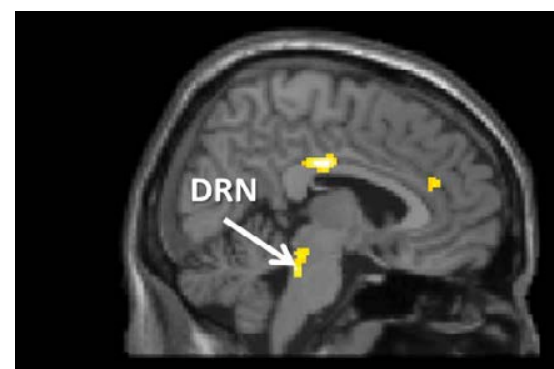

$X=6 \mathrm{~mm}$

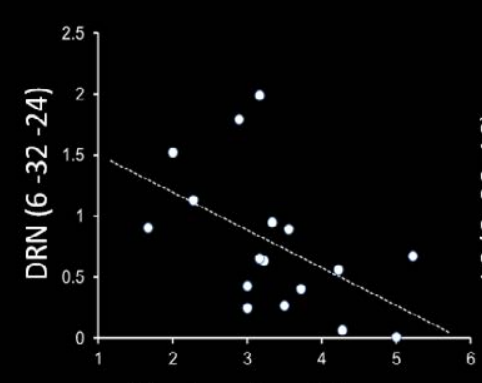

Attachment-anxiety score

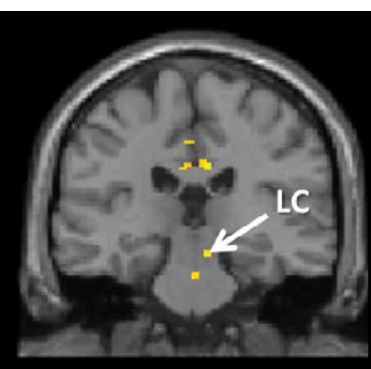

$y=-26 \mathrm{~mm}$

Figure 3: Sagittal view $(x=6 \mathrm{~mm})$ and coronal view $(y=-26 \mathrm{~mm})$ of whole-brain activity. The ACC, PCC, and PRN were significantly activated by viewing the partner's face compared with viewing the face of unknown females' faces. 
2004 [22]); Figure 5), and the PCC ((1 -25 28) [TAL]: (3 -22 29) [MNI], p = 0.000, FWE, early-stage love (Aron et al., 2005 [8]); Figure 4) were significantly activated.

\section{- Correlations with subjective ratings}

Correlation analyses showed that DRN and LC activation were both negatively correlated with the ECR anxiety scores (DRN: adjusted $\mathrm{R}^{2}=$ $0.21, \mathrm{t}=-2.31, \mathrm{p}=0.035 ; \mathrm{S}-\mathrm{W}$ statistic $=0.915$, $\mathrm{p}=0.122 ; \mathrm{D}-\mathrm{W}$ statistic $=2.06 / \mathrm{LC}$ : adjusted $\mathrm{R}^{2}=0.19, \mathrm{t}=-2.20, \mathrm{p}=0.044 ; \mathrm{S}-\mathrm{W}$ statistic $=$ $0.956, \mathrm{p}=0.551 ; \mathrm{D}-\mathrm{W}$ statistic $=2.78$; Figure $3)$. The IPL activation was negatively correlated with PLS scores (adjusted $\mathrm{R}^{2}=0.27, \mathrm{t}=-2.62$, $\mathrm{p}=0.019 ; \mathrm{S}-\mathrm{W}$ statistic $=0.960, \mathrm{p}=0.632$; $\mathrm{D}-\mathrm{W}$ statistic $=1.88$; Figure 5). Moreover, SN/VTA activity ((14 -22 -14) [TAL] ((16 -23 -18) $[\mathrm{MNI}]$ ), maternal love (Bartels and Zeki, 2004 [22])) negatively correlated with the ECR anxiety score (adjusted $\mathrm{R}^{2}=0.34, \mathrm{t}=-2.78, \mathrm{p}=$ $0.014 ; \mathrm{S}-\mathrm{W}$ statistic $=0.974, \mathrm{p}=0.891 ; \mathrm{D}-\mathrm{W}$ statistic $=2.62$; Figure 5) .

\section{Discussion}

Bowlby have argued that individuals develop cognitive-affective representations or internal working models of their experiences in attachment relationships from infancy onwards [28]. Individuals who have reliably received sensitive care are disposed to develop generally positive representations of themselves and others, or in other words, secure attachment. In contrast, individuals with a history of negative experiences with attachment figures can develop conditional attachment strategies, which take two fundamentally different forms. One is a hyperactivated attachment system, characterized by high anxiety and the use of excessive attempts to get attention and care from another, and the other is a deactivated attachment system, characterized by avoidance of closeness and support, seeking and maintaining a strong reliance on the self $[29,30]$. In our study, attachment-related anxiety was negatively correlated with several regions in the brainstem (Figure 3,5), whereas

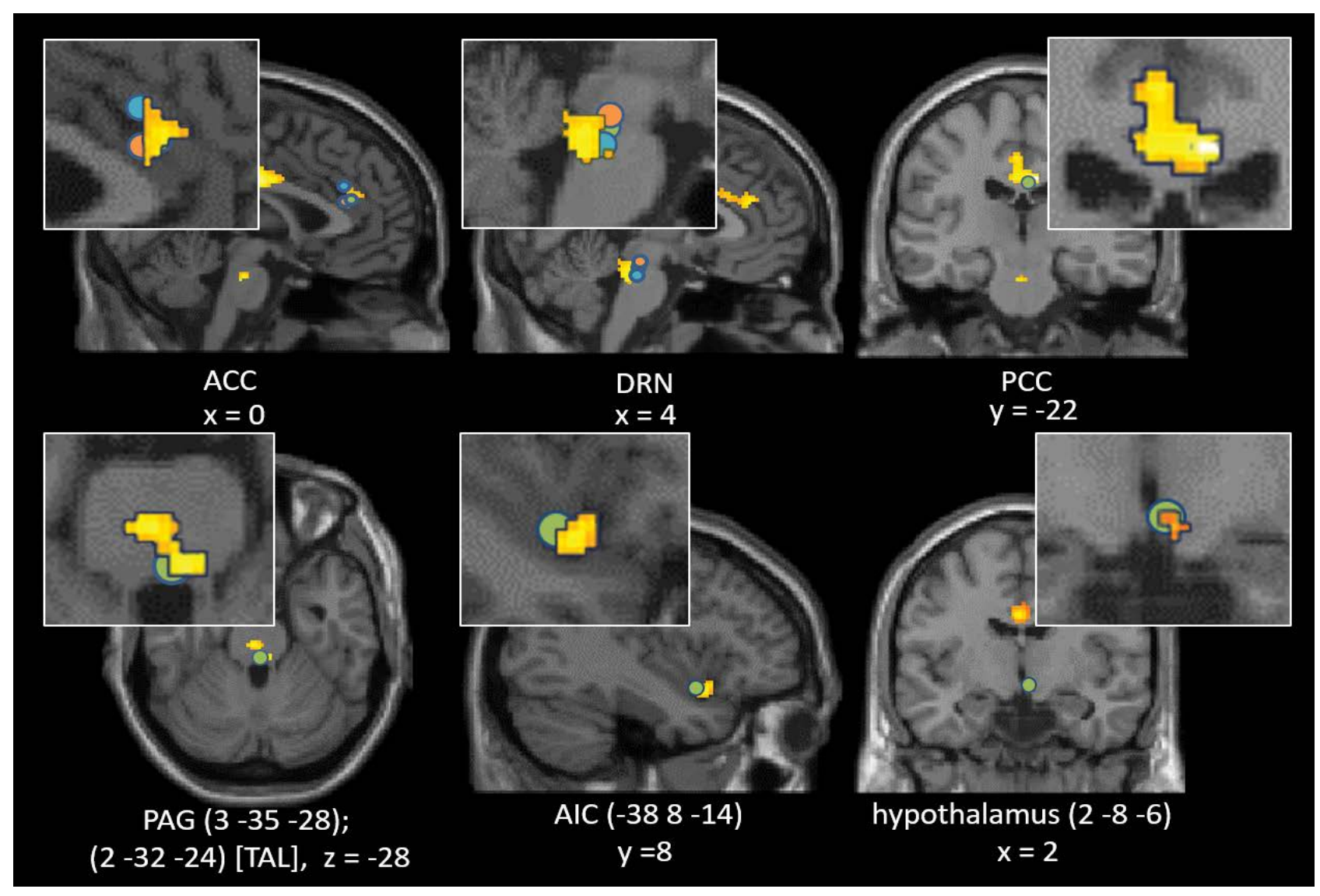

Figure 4: Superposition of ROls which showed significance in the ROI analysis and the corresponding clusters in the whole brain. Clusters of the ACC, the PCC, and the DRN are represented with a height threshold of $p<0.001$ and an extent threshold of $p<0.05$ (FDR, corrected). The PAG, AIC, and hypothalamus ROIs are superposed on the corresponding cluster, respectively (PAG, AIC, $p<0.001$, clusters $>10$; hypothalamus, $p<0.005$, clusters $>$ 10). Each box shows the superposition for the corresponding cluster. 


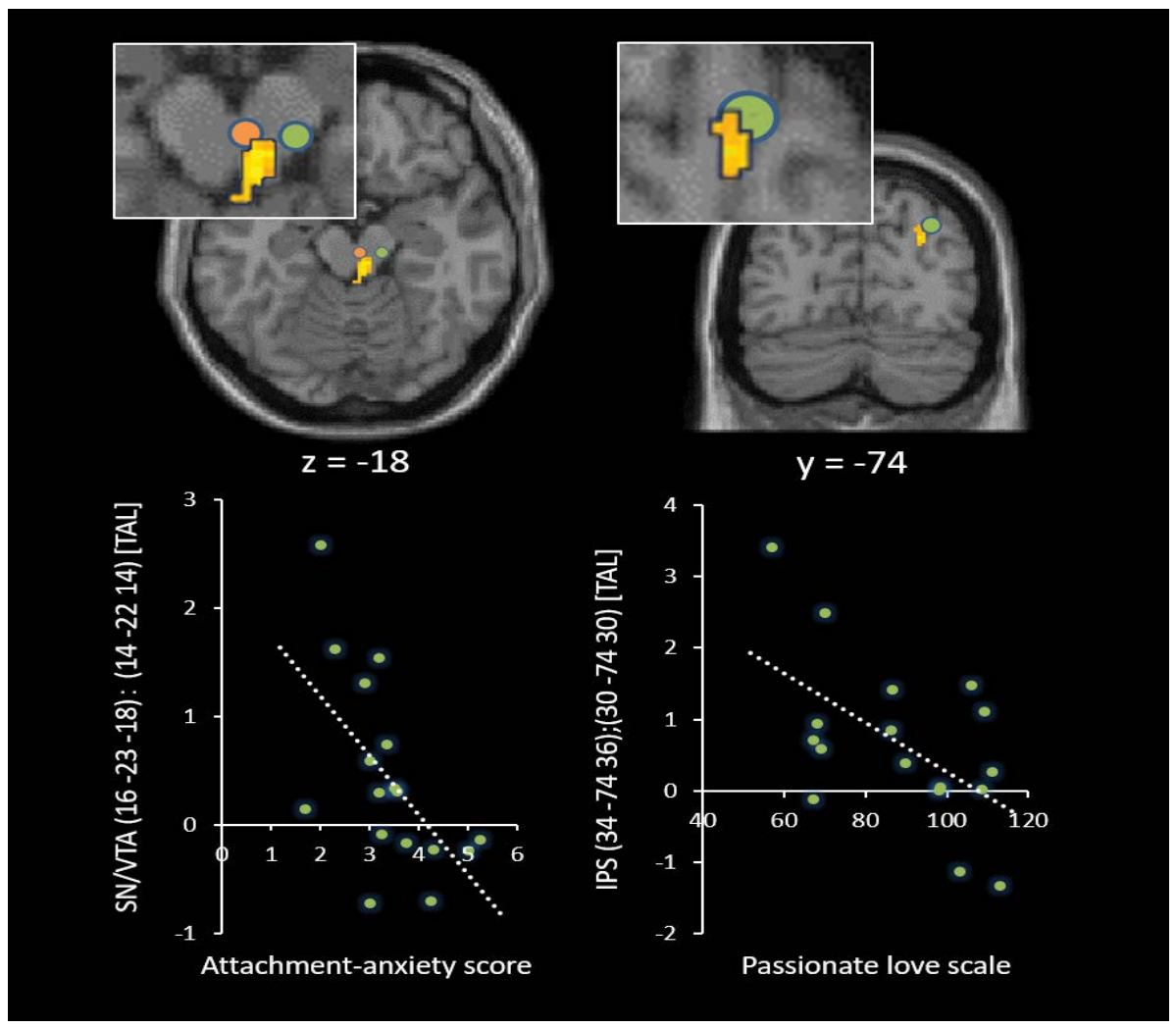

Figure 5: Significant negative correlations between SN/VTA activity showing significance in the ROI analysis and attachment-related anxiety (left), and between IPS activity showing significance in the ROI analysis and PLS scores (right) $(p<0.001$, clusters $>10)$. Each box shows the superposition for the corresponding cluster.

attachment-related avoidance did not show any significant relationships with specific regions. Our participants had 6-year relationships, on average, and they were classified as "being in highly passionate love" according to the PLS. Furthermore, the ROI analyses showed that the DRN (Acevedo et al., 2011 [9]), the PAG (Acevedo et al., 2011 [9]; Bartels and Zeki, 2004 [22]), the hypothalamus (Acevedo et al., 2011 [9]), the AIC (Acevedo et al., 2011 [9]), the SN/ VTA (Acevedo et al., 2011 [9]; Bartels and Zeki, 2004 [22]), the ACC (Bartels and Zeki, 2004 [22]; Bartels and Zeki, 2000 [21], Aron et al., 2005 [8]), the IPS/IPL (Bartels and Zeki, 2004 [22]), and the PCC (Aron et al., 2005 [8]) were significantly activated when photos of partners were viewed, showing that brain activity in our study was more similar to that observed in longterm intense romantic love and maternal love than that found in early-stage romantic love. Among the activated brainstem regions, there were individual differences in the activity of some regions, depending on the degree of attachmentrelated anxiety. These brain regions were the dopaminergic SN/VTA, the serotonergic DRN, and the adrenergic LC.
The SN/VTA is centrally placed in a wider motivational/reward network associated with behaviors necessary for survival [3133]. Findings from diverse fMRI studies of romantic love provide strong evidence that the dopaminergic reward system, including the SN/ VTA, is associated with early-stage romantic love, long-term romantic love, and maternal love. Goal-directed behavior, necessary to obtain rewarding stimuli, is consistent with characteristics of pair bonds and romantic love as being a motivation associated with a specific set of behavioral characteristics, such as proximity-seeking, working to make the partner happy, and rejection of unfamiliar conspecifics $[8,34]$. These behaviors serve to initiate, maintain, and protect the pair bond as evidenced by research using animal models [35-38]. Therefore, attachment-related anxiety may decrease the reward value of partners and the motivation for maintaining and developing relationships. The DRN is a serotonin-rich site, and serotonin is implicated in love and pair bonding. "Felt security" is one of the set goals of the attachment system [39], and pain and stress reduction is associated with the representation 
of an attachment figure [12,40]. Moreover, reduction of serotonergic functions is associated with heightened rates of "neuroticism" [41], which was positively correlated with attachmentrelated anxiety in our study. Furthermore, stress has been shown to downregulate serotonin receptors in the raphe nuclei [42]. Depletion of central serotonin is also found in several psychiatric disorders including obsessivecompulsive disorder (OCD) [43], depression [44], eating disorders [45], and anxiety disorders [46]. Accordingly, attachment-related anxiety is thought to increase insecure feelings towards the relationship with a partner. Moreover, recent promising results strengthen the pivotal role of serotonin in reward processing. DRN neurons provide a tonic firing pattern related to expected and received reward values, whereas SN/VTA neurons exhibit phasic responses related to reward-prediction errors. The PRN also plays a critical role in affective regulatory functions [47-50]. Patients with bipolar disorders exhibit reduced serotonergic functioning in the PRN $[47,48]$, and both the anatomical and functional connectivity of the PRN with other affective networks predicts the affective states and emotional reactivity of healthy persons [49]. The DRN and PRN show different brain projections [50], and animal evidence indicates that acute stress alters serotonergic functions in the PRN but not the DRN [51]. In fact, the PRN did not correlate with attachment-anxiety in the present study, although it was significantly activated by viewing the partner compared with unknown females. The LC is the site of synthesis and release of the neurotransmitter norepinephrine, and the neurons of the LC are important in a variety of cognitive, affective, and other behavioral functions, as well as associated clinical dysfunctions (e.g., depression, anxiety, sleep and circadian disorders [52]). Compared to healthy controls, depressed individuals display reduced gray matter density in this region [53-55]. The LC is also one of the primary sites mediating the stress response as well as a site of action of anti-depressant drugs [56]. Norepinephrine is thought to act as a modulatory agent, modulating serotonin and dopamine release through projections into the SN/VTA and the DRN $[55,57,58]$. Furthermore, there is evidence that a bias toward negative memories and emotions in depression may be related to norepinephrine, and that potentiation of norepinephrine results in increased recognition of positive emotions [59]. Furthermore, the LC plays a very specific role in retrieval of emotional memories and saliency
[60]. These facts suggest that attachment-related anxiety increases negative emotions associated with the retrieval of emotional memories regarding the relationship with a partner.

In addition, the ACC (whole-brain and ROI analyses; Figure 2 and Figure 4) and the AIC (ROI; Figure 4) were significantly activated in the present study. The AIC and ACC contain a specialized class of neurons, the Von Economo neurons (VENs), which display distinctive anatomical and functional properties [61,62]. The VENs have wider axons, which can facilitate rapid relay of signals from the AIC and ACC to other cortical regions [63], endowing the salience network with distinct mechanisms for signaling within and across the network. This network, together with interconnected brain networks, contributes to a variety of complex brain functions, including communication, social behavior, and self-awareness through the integration of sensory, emotional, and cognitive information [64-66]. ACC activation has been commonly reported in studies of early-stage romantic love [8,21] (Aron et al., 2005; Bartels \& Zeki, 2000), long-term romantic love [9] (Acevedo et al., 2011), maternal love [22] (Bartels \& Zeki, 2004), and unconditional love [67] (Beauregard et al., 2009). Moreover, some studies have implicated the ACC in cardinal traits of romantic love: obsessive thinking [68-70] and pleasant touching [71]. Furthermore, positive correlations with the ACC as well as the AIC and the striatum have been shown for trials in which another individual gains at the expense of oneself [72], suggesting that this activity reflects highly empathetic attitudes towards their partner. The insula has been highlighted in numerous studies involving emotion and is thought to be important for social behaviors, socioemotional behaviors, and empathy [73]. Moreover, the insula is involved in processing caress-like touching between individuals [74], and is thought to be important for affiliative behavior between individuals. In our study, the left AIC ROI was significantly activated, suggesting parasympathetic activity associated with viewing the partner, since left insula stimulation produces parasympathetic effects (bradycardia and blood pressure depression), whereas stimulation of the right insula produces sympathetic effects (tachycardia and blood pressure elevation) [75] (Oppenheimer, et al., 1992). Moreover, PAG activation mediates the autonomic changes associated with emotions, and the resulting changes in the physiological state of the body are 
fed back through the thalamus to the insula and the ACC [58]. Previous fMRI studies [22,76] support the view that the PAG is involved in human maternal behavior. This structure is heavily connected with various limbic regions and contains a high density of oxytocin receptors [77]. Oxytocin is a hypothalamic neuropeptide that has been widely implicated in the regulation of positive social interactions, social bonding, and maternal responsiveness in several mammalian species, including humans [78]. In addition, PAG activation is involved in feeling unconditional love towards individuals with intellectual disabilities [67], and men display significantly higher PAG rCBF (regional cerebral blood flow) than women when experiencing an orgasm [79]. These observations suggest that the PAG is involved in caregiving motivation and empathy. Furthermore, IPS activation was negatively correlated with PLS scores in our study. The IPS shows activation when individuals assess physical distance between themselves and external objects, suggesting that the IPS is involved in self-referential (egocentric) spatial coding of external objects/the world $[80,81]$. Furthermore, the parietal cortex subserves analytic functions in evaluating social relationships and distance including personal space [82]. Neurons in the IPS exhibit activities that appear to represent values regarding other agents such as females, subordinates, and dominant monkeys [83]. The decreased activity of the right IPS in our study is suggested to correspond to the subjective passionate feelings towards the partner. Moreover, the PCC is involved in autobiographical memory retrieval when listening to familiar names (such as that of a spouse, parent, or child) vs. non-familiar person names [84], or when viewing images of a familiar child vs. an unfamiliar child [85]. In addition, the PCC plays a critical role in regulating the focus of attention [86-88].

In our study, there were clear negative correlations between brainstem activity and attachment-related anxiety while subjects were viewing their partner; the brainstem activity was more decreased in highly anxious individuals compared with less anxious individuals, even among subjects who were intensely in love with their partner and showed brain activity similar to that observed in long-term intense romantic love and maternal love. The identified brainstem regions (SN/VTA, DRN, and LC) are the primary sites of neurotransmitters which modulate basic functions of survival, such as reward/motivation, positive emotion, and maintenance of secure states, and also play key roles for maintenance of secure relationships with a partner. These findings might be useful to assessment of the risk of breakdowns by factors involved in the attachment style.

\section{References}

1. Garcia CY. Temporal course of the basic components of love throughout relationships. Psychol. Spain 2(1), 76-86 (1988).

2. Berscheid E. Love in the fourth dimension. Annu. Rev. Psychol 61(1), 1-25 (2010).

3. Starka L. Endocrine factors of pair bonding. Prague. Med. Rep 108, 297-305 (2007).

4. Marazziti D, Akiskal HS, Rossi A, et al. Alteration of the platelet serotonin transporter in romantic love. Psychol. Med 29(1), 741-745 (1999).

5. Marazziti D, Canale D. Hormonal changes when falling in love. Psychoneuroendocrinology 29(1), 931-936 (2004).

6. Emanuele $E$, Politi $P$, Bianchi $M$, et al. Raised plasma nerve growth factor levels associated with early-stage romantic love. Psychoneuroendocrinology 31(1), 288 -294 (2006).

7. Esch T, Stefano GB. Love promotes health. Neuro. Endocrinol. Lett 26(1), 264-267 (2005).
8. Aron A, Fisher H, Mashek DJ, et al. Reward, motivation, and emotion systems associated with early-stage intense romantic love. J. Neurophysiol 94(1), 327-337 (2005).

9. Acevedo BP, Aron A, Fisher HE, et al. Neural correlates of long-term intense romantic love. Soc. Cogn. Affect. Neurosci 7(1), 145-59 (2012).

10. Kiecolt-Glaser J, Newton T. Marriage and health: His and hers. Psychol. Bull 127(1), 4, 472-503 (2011).

11. Proulx $C$, Helms $H$, Buehler $C$. Marital quality and personal well-being: A meta-analysis. $J$ Marriage. Fam. 69(1), 576-593 (2007).

12. Coan JA, Schaefer HS, Davidson RJ. Lending a hand: Social regulation of the neural response to threat. Psychol. Sci 17(1), 1032-1039 (2006).

13. Riehl-Emde A, Thomas V, Willi J. Love: An important dimension in marital research and therapy. Fam. Process 42(1), 253-267 (2003).

14. Brennan KA, Clark CL, Shaver PR. Self-report measurement of adult romantic attachment: An integrative overview. In J. A. Simpson \& W. S. Rholes (Eds.), Attachment theory and close relationships 46-76. New York: Guilford Press
(1998).

15. Campbell L, Simpson JA, Boldry J, et al. Perceptions of conflict and support in romantic relationships: The role of attachment anxiety. J Pers. Soc. Psychol 88(1), 510-531 (2005).

16. Davila J, Karney BR, Bradbury TN. Attachment change processes in the early years of marriage. J Pers. Soc. Psychol 76(1), 783-802 (1999).

17. Feeney JA. Attachment, marital interaction, and relationship satisfaction: A diary study. Pers. Relatsh 9(1), 39-55 (2002).

18. Shaver PR., Schachner DA, Mikulincer $M$. Attachment style, excessive reassurance seeking, relationship processes, and depression. Pers. Soc. Psychol. Bull 31 (1), 343359 (2005).

19. Mikulincer M, Erev I. Attachment style and the structure of romantic love. Br. J. Soc. Psychol 30(1), 273-291 (1991).

20. Campbell L, Simpson JA, Boldry J, et al. Perceptions of conflict and support in romantic relationships: The role of 
attachment anxiety. J. Pers. Soc. Psychol 88(1), 510-531 (2005).

21. Bartels A, Zeki S. The neural basis of romantic love. Neuroreport 11(1), 3829-3834 (2000).

22. Bartels A, Zeki S. The neural correlates of maternal and romantic love. Neuroimage 21(1), 1155-1166 (2004).

23. Hatfield E, Sprecher S. Measuring passionate love in intimate relations. $J$. Adolesc 9(1), 383-410 (1986).

24. John OP, Srivastava S. The Big-Five trait taxonomy: History, measurement, and theoretical perspectives. In L.A. Pervin \& O.P. John (Eds.), Handbook of personality: Theory and research $(2,102-138)$. New York: Guilford Press (1999).

25. Fowler D, Freeman D, Smith B, et al. The Brief Core Schema Scales (BCSS): psychometric properties and associations with paranoia and grandiosity in nonclinical and psychosis samples. Psychol. Med 36(1), 749-759 (2006)

26. Fraley RC, Waller NG, Brennan KA. An itemresponse theory analysis of self-report measures of adult attachment. J. Pers. Soc. Psychol 78(1), 350-365 (2000).

27. Fraley RC, Chris ME, Heffernan ME, et al. The Experiences in Close RelationshipsRelationship Structures Questionnaire: A Method for Assessing Attachment Orientations Across Relationships. Psychol. Assess 23(1), 615-625 (2011).

28. Bowlby, J., 1973. Attachment and loss: Vol. 2. Separation: Anxiety and anger. New York: Basic Books.

29. Mikulincer M, Shaver PR. Attachment in adulthood: Structure, dynamics, and change. New York: Guilford Press (2007).

30. Mikulincer M, Shaver PR. An attachment and behavioral systems perspective on social support. (Special Issue: Social Support.) J. Soc. Pers. Relatsh 26(1), 7-19 (2009).

31. Camara E, Rodriguez-Fornells A, Ye Z, et al. Reward networks in the brain captured by connectivity measures. Front. Neurosci 3(1), 350-362 (2009).

32. Delgado MR, Locke HM, Stenger VA, et al. Dorsal striatum responses to reward and punishment: Effects of valence and magnitude manipulations. Cogn. Affect. Behav. Neurosci 3(1), 27-38 (2003)

33. O'Doherty J, Dayan P, Schultz J, et al. Dissociable roles of ventral and dorsal striatum in instrumental conditioning. Science 304(1), 452-454 (2004).

34. Fisher HE. Lust, attraction, and attachment in mammalian reproduction. Hum. Nat 9(1) 23-52 (1998).
35. Aragona, BJ, Liu Y, Curtis JT, et al. A critical role for nucleus accumbens dopamine in partner-preference formation in male prairie voles. J. Neurosci 23(1), 3483-90 (2003).

36. Carter CS, DeVries AC, Getz LL. Physiologica substrates of mammalian monogamy: the prairie vole model. Neurosci. Biobehav. Rev 19(1), 303-314 (1995).

37. Wang ZX, Hulihan TJ, Insel TR. Sexual and social experience is associated with different patterns of behavior and neural activation in male prairie voles. Brain. Res 767(1), 321-332 (1997).

38. Winslow J, Hastings N, Carter CS, et al. A role of central vasopressin in pair bondings in monogamous prairie voles. Nature 365(1), 545-548 (1993).

39. Sroufe LA Waters E. Attachment as an organizational construct. Child. Dev 48(1), 1184-1199 (1977).

40. Master SL, Eisenberger NI, Taylor SE, et al. A picture's worth. Partner photographs reduce experimentally induced pain. Psychol. Sci 20(1), 1316-1318 (2009)

41. Sen S, Burmeister M, Ghosh D. Metaanalysis of the association between a serotonin transporter promoter polymorphism (5-HTTLPR) and anxietyrelated personality traits. Am. J. Med. Genet. B. Neuropsychiatr Genet 127(1), 85-89 (2004).

42. Fuchs $\mathrm{E}$, Flügge $\mathrm{G}$. Chronic social stress: effects on limbic brain structures. Physiol. Behav 79(1), 417-427 (2003).

43. Micallef J, Blin O. Neurobiology and clinical pharmacology of obsessive-compulsive disorder. Clin Neuropharmacol 24(1), 191207 (2001).

44. Young SN, Leyton M. The role of serotonin in human mood and social interaction. Insight from altered tryptophan levels. Pharmacol. Biochem. Behav. 71(1), 857-865 (2002).

45. Bailer UF, Frank G, Henry S, et al. Serotonin transporter binding after recovery from eating disorders. Psychopharmacology 195(1), 315-324 (2007).

46. Leonardo ED, Hen R. Genetics of affective and anxiety disorders. Annu. Rev. Psychol 57(1), 117-137 (2006)

47. Cannon DM, Ichise M, Rollis D, et al. Serotonin transporter binding in bipolar disorder assessed using [11 C] DASB and positron emission tomography. Biol. Psychiatry 60(1), 207-217 (2006).

48. Cannon DM, Ichise $M$, Rollis $D$, et al. Elevated serotonin transporter binding in major depressive disorder assessed using positron emission tomography and [11 C] DASB; comparison with bipolar disorder. Biol. Psychiatry 62(1), 870-877 (2007).
49. Lee TM, Sun D, Wong NM, et al. A pontine region is a neural correlate of the human affective processing network. EBioMedicine 2(1), 1799-1805 (2015).

50. Cooper JR, Bloom FE, Roth RH. The biochemical basis of neuropharmacology. Oxford University Press, USA (2003).

51. Vollmayr B, Keck S, Henn FA, et al. Acute stress decreases serotonin transporter mRNA in the raphe pontis but not in other raphe nuclei of the rat. Neurosci Lett 290(1) 109-112 (2000).

52. Aston-Jones G, Iba M, Clayton E, et al. The locus coeruleus and regulation of behavioral flexibility and attention: clinical implications. Brain Norepinephrine: Neurobiology and Therapeutics, ed. Gregory A. Ordway, Michael A. Schwartz and Alan Frazer. Published by Cambridge University Press. Cambridge University Press (2007)

53. Chan-Palay V, Asan E. Quantitation of catecholamine neurons in the locus coeruleus in human brains of normal young and older adults and in depression. J Comp Neurol 287(1), 357-372 (1989).

54. Arango V, Underwood MD, Mann JJ. Fewer pigmented locus coeruleus neurons in suicide victims: preliminary results. Biol. Psychiatry 39(1), 112-120 (1996).

55. Ressler KJ, Nemeroff CB. Role of norepinephrine in the pathophysiology and treatment of mood disorders. Biol Psychiatry 46(1), 1219-1233 (1999).

56. Brady LS. Stress, antidepressant drugs, and the locus coeruleus. Brain Res Bull 35(1), 545-556 (1994).

57. Plaznik A, Kostowski W. The interrelationship between brain noradrenergic and dopaminergic neuronal systems in regulating animal behavior: possible clinical implications. Psychopharmacol Bull 19(1), 5-11 (1983).

58. Grenhoff J, Nisell M, Ferr S, et al. Noradrenergic modulation of midbrain dopamine cell firing elicited by stimulation of the locus coeruleus in the rat. J Neural Transm 93(1), 11-25 (1993).

59. Harmer CJ, Hill SA, Taylor MJ, et al. Toward a neuropsychological theory of antidepressant drug action: increase in positive emotional bias after potentiation of norepinephrine activity. Am J Psychiatry 160(1), 990-992.

60. Sterpenich V, D'Argembeau A, Desseilles M, et al. The Locus Ceruleus Is Involved in the Successful Retrieval of Emotional Memories in Humans. J Neurosci 26(1), 7416-7423 (2006).

61. Allman JM, Watson, KK, Tetreault NA, et al. Intuition and autism: a possible role for Von Economo neurons. Trends. Cogn. Sci 9(1), 


\section{7-73 (2005).}

62. Nimchinsky EA, Gilissen E, Allman JM, et al. A neuronal morphologic type unique to humans and great apes. Proc. Natl. Acad. Sci. USA 96(1), 5268-5273 (1999).

63. Allman JM, Tetreault NA, Hakeem AY, et al. The von Economo neurons in frontoinsular and anterior cingulate cortex in great apes and humans. Brain. Struct. Funct 214(1), 495517 (2010).

64. Craig AD How do you feel--now? The anterior insula and human awareness. Nat. Rev. Neurosci 10(1), 59-70 (2010).

65. Gogolla N, Takesian AE, Feng G, et al. Sensory integration in mouse insular cortex reflects GABA circuit maturation. Neuron 83(1), 894905 (2014).

66. Menon V, Uddin LQ. Saliency, switching, attention and control: A network model of insula function. Brain. Struct. Funct 214(1), 655-667 (2010).

67. Beauregard $M$, Courtemanche J, Paquette V, et al. The neural basis of unconditional love. Psychiatry. Res. 172(1), 93-98 (2009).

68. Bush G, Frazier JA, Rauch SL, et al. Anterior cingulate cortex dysfunction in attentiondeficit/hyperactivity disorder revealed by fMRI and the counting Stroop. Biol. Psychiatry 45(1), 1542-1552 (1999).

69. Rauch SL, Whalen PJ, Curran T, et al. Probing striato-thalamic function in obsessivecompulsive disorder and Tourette syndrome using neuroimaging methods. Adv. Neurol 85(1), 207-224 (2001).

70. Ursu S, Stenger VA, Shear MK, et al. Overactive action monitoring in obsessive compulsive disorder: Evidence from functional magnetic resonance imaging. Psychol. Sci 14(1), 347-353 (2003).
71. Rolls ET, O'Doherty J, Kringelbach ML, et al. Representations of pleasant and painful touch in the human orbitofrontal and cingulate cortices. Cereb Cortex 13(1), 308-317 (2003).

72. Fahrenfort JJ, van Winden F, Pelloux B, et al. Neural correlates of dynamically evolving interpersonal ties predict prosocial behavior. Front. Neurosci 6 (2012).

73. Kurth F, Zilles K, Fox PT, et al. A link between the systems: functional differentiation and integration within the human insula revealed by meta-analysis. Brain. Struct. Funct 214(1), 519-534 (2010).

74. Olausson $\mathrm{H}$, Lamarre $\mathrm{Y}$, Backlund $\mathrm{H}$, et al. Unmyelinated tactile afferents signal touch and project to insular cortex. Nat. Neurosci 5(1), 900-904 (2002).

75. Oppenheimer SM, Gelb A, Girvin JP, et al. Cardiovascular effects of human insular cortex stimulation. Neurology 42(1), $1727-$ 1732 (1992).

76. Noriuchi M, Kikuchi Y, Senoo A. The functiona neuroanatomy of maternal love: mother's response to infant's attachment behaviors. Biol. Psychiatry 63(1), 415-23 (2008).

77. Jenkins JS, Ang VT, Hawthorn J, et al. Vasopressin, oxytocin and neurophysins in the human brain and spinal cord. Brain. Res 291(1), 111-117 (1984).

78. Olazábal DE, Young LJ. Oxytocin receptors in the nucleus accumbens facilitate "spontaneous" maternal behavior in adult female prairie voles. Neuroscience 141, 559568 (2006).

79. Georgiadis JR, Reinders AA, Paans AM. Men versus women on sexual brain function: prominent differences during tactile genital stimulation, but not during orgasm. Hum. Brain. Mapp 30(1), 3089-3101 (2009).
80. Connolly JD, Andersen RA, Goodale MA, FMRI evidence for a 'parietal reach region' in the human brain. Exp. Brain. Res 153(1), 140-145 (2003)

81. Medendorp WP, Goltz HC, Crawford JD, et al. Integration of Target and Effector Information in Human Posterior Parietal Cortex for the Planning of Action. J. Neurophysiol 93(1), 954962 (2005).

82. Chiao JY, Harada T, Oby ER, et al. Neural representations of social status hierarchy in human inferior parietal cortex. Neuropsychologia 47(1), 354-363 (2009).

83. Klein JT, Deaner RO, Platt ML. Social target value signals in parietal cortex. Curr. Biol 18(1), 419-419 (2008).

84. Maddock RJ, Garrett AS, Buonocore MH Remembering familiar people: the posterior cingulate cortex and autobiographical memory retrieval. Neuroscience 104(1), 667676 (2001).

85. Leibenluft E, Gobbini MI, Harrison T, et al. Mothers' neural activation in response to pictures of their children and other children Biol. Psychiatry 56(1), 225-32 (2004).

86. Gusnard DA, Raichle ME. Searching for a baseline: functional imaging and the resting human brain. Nat. Rev. Neurosci 2(1), 685-694 (2001).

87. Hampson M, Driesen NR, Skudlarski P, et al. Brain connectivity related to working memory performance. J Neurosci 26(1), 13338-13343 (2006).

88. Hahn B, Ross, TJ, Stein EA. Cingulate activation increases dynamically with response speed under stimulus unpredictability. Cereb. Cortex 17(1), 1664-1671 (2007). 